in numbers may be accounted for by the general shortage of qualified engineers and also by the fact that housing difficulties, etc., are a deterrent to those wishing to change their jobs. More than 10 per cent of the engineers placed in positions were more than fifty years old, and the Bureau now recommends persons without consideration of age unless the prospective employer specifies any conditions of age. The Bureau is desirous that an employer should make a personal review of its register so that a detailed discussion can be made of the suitability of a candidate for a particular situation. During the year more placings were made than previously, and a record total for appointment fees was achieved. However, owing to rising costs the expenses of running the Bureau were not covered by income, and liabilities could only be met by generous donations from industry, which totalled $\mathfrak{E 2 . 5 6 3}$, as compared with $£ 1,041$ in 1950 .

\section{Multi-sensory Aids for Teaching Mathematics}

For some years the mathematical staff of the Gateway School for Boys, Leicester, have shown much energy in developing visual and other aids for the teaching of mathematics. These include a series of film-strips on such subjects as the quadratic graph, from experiment to law, the history of calculation, an area construction, graphical solution of equations, permutations, an introduction to loci, how to read mathematical tables, and an introduction to the calculus. There is also a transparent 'Perspex' device containing coloured fluid which just fills a circular cavity; by tilting the device the fluid leaves this cavity and flows into another of rectangular shape, thus evaluating the area of a circle. The school also publishes Mathematical Pie, a small magazine containing a mathematical crossword and other material, chiefly of the puzzle type. Of course, similar activities are being carried on elsewhere, for example, in Switzerland, where J. L. Nicolet has produced a series of silent films which impart geometrical ideas by the dynamic method used in cartoon films. The time has now come to co-ordinate these activities. Those who are interested in the formation of an association for multi-sensory aids for the teaching of mathematics are asked to write to R. H. Collins, 47 Edward Avenue, Leicester.

\section{Annals of Physical Medicine}

The first issue of a new quarterly, the Annals of Physical Medicine (1,.No. 1, 36 ; January 1952. $6 s$. net or $21 s$. net annual subscription. London: Headley Bros., Ltd.) marks the courageous decision of the British Association of Physical Medicine to publish its own journal. This Association was founded, as Lord Horder explains in his foreword to this issue, nine years ago "to encourage the study of the action of physical agents and their application in the promotion of Health; in the prevention and treatment of illness and injury ; and in the restoration to fitness". Twenty-five years ago this kind of work was called physiotherapy, and the treatment given was passive, palliative and largely empirical, the bulk of the patients treated being chronic sufferers from diseases of the locomotor system. Nowadays physical medicine includes physical education, rehabilitation and resettlement, as well as the use of physical agents for both diagnosis and treatment; and many more diseases are nowadays treated by these methods. Research, as this issue of the Annals shows, is also a major activity of the members of the Association, and every effort is being made to improve the status of the specialist in physical medicine and to stimulate the universities to increase their efforts on behalf of what is, nowadays, an important branch of medicine. In this first issue of the Annals there are papers on the effects of microwaves and on the ambulant treatment of the complications of varicose veins and allied conditions that have defeated all surgical measures; and there are short reports on the International Federation of Physical Medicine, constituted in London in 1950, and on the International Congress of Physical Medicine to be held in London in July. The rapid expansion of this branch of medicine is a feature of modern medical development and deserves hearty and continued support.

\section{Nest-Boxes}

The British Trust for Ornithology (c/o Edward Grey Institute, 91 Banbury Road, Oxford) has produced a field guide to describe the best and simplest designs of nest-box shown by experience to be effective in attracting hole- or ledge-nesting species which the bird-lover may wish to encourage or the scientific bird-watcher to study more conveniently than is possible under natural conditions. It has been written by Edwin Cohen and Bruce Campbell and compiled from a variety of sources, published and unpublished, at the request of the Trust. Only designs which can be cheaply constructed have been included, while guidance is also given on the keeping of records and other types of artificial nest-sites. Each section is preceded by a tabular summary intended to help the observer to select quickly the designs most suitable for those species which occur in his neighbourhood and which he wants to attract to his boxes. A bibliography includes some references to books and papers dealing with the origins and history of nest-boxes.

\section{The Worker in Industry}

THE ten centenary lectures for 1951, entitled "The Worker in Industry", which were given last year under the auspices of the Ministry of Labour and National Service in association with the Ministry's exhibition in London on "Manpower: the Human Factor in Industry", have now been collected in pamphlet form and made conveniently available to a wider circle than their original audiences (pp. 106. London : H.M. Stationery Office. 3s. 6d. net). Their keynote is practical rather than academic, and successive lectures deal with youth and man-power needs in Great Britain; eliminating the wastage of disablement; the effect of environment on the health and efficiency of the industrial worker; technical and scientific man-power; problems of wages policy; the contribution of the International Labour Organization; self-government in industry; the employment of the older worker; the human factor in accident prevention; and training for industry. A foreword contributed by Sir Walter Monckton expresses the hope that publication of the lectures will both stimulate thought and help to guide action in these matters.

\section{Science Masters' Association: Annual Meeting of the Scottish Branch}

THE annual meeting of the Scottish Branch of the Science Masters' Association was held in University College, Dundee, during April 15-17, with MajorGeneral D. W. Wimberley, principal of the College, 